\title{
Notes on Experiments in the Keeping of Plankton Animals under Artificial Conditions.
}

\author{
By
}

\author{
L. R. Crawshay, M.A.
}

TABLE OF CONTENTS.

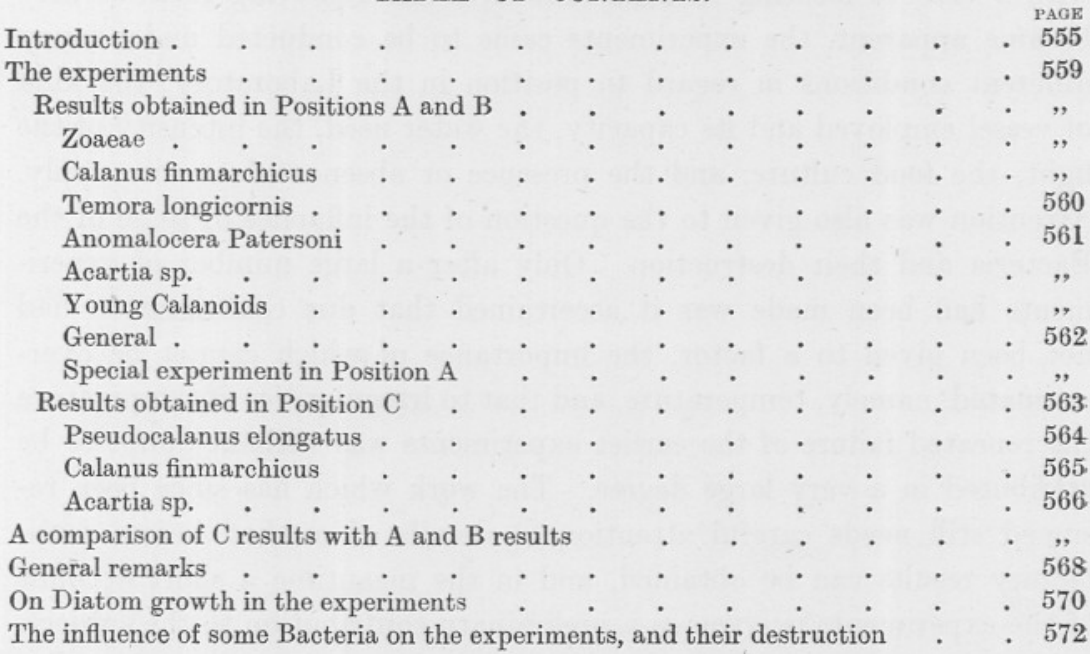

\section{Introduction.}

THE experiments referred to in the following pages were carried out by the wish of the Director at the Plymouth Laboratory, between June, 1912, and February, 1913. They were undertaken with a view to keeping under observation some of the smaller zooplankton, and particularly the Copepoda, in order that they might be followed through the different stages of their life cycle. After a long series of disappointing results, the experiments were unavoidably interrupted at a time when apparently the chief obstacles to success had been located and largely overcome.

Continued observation of these small animals has only in the last few years been rendered certainly possible by the work of Dr. Allen on the culture of the marine Diatoms, which form the chief food supply of the great majority of them, and it is not surprising that until the problem of obtaining and keeping a suitable food culture was settled, attempts to keep 
Copepoda alive in the Laboratory met with little success. Mention may here be made of one important result obtained by Dr. Allen himself, in the course of his Diatom experiments. In a flask of 1000 c.c. in capacity he kept, between August and September, 1905, some specimens of Calanus finmarchicus alive on a mixed Diatom culture for a period of about seven weeks, and obtained from them many nauplii, two of which developed into young Calanus, of which the exact life period was not recorded.* It was uncertain how far the exact conditions under which this experiment was carried out had been essential to its success, and with a view to locating harmful influences and removing them as they became apparent, the experiments came to be conducted under many different conditions in regard to position in the Laboratory, the kind of vessel employed and its capacity, the water used, the intensity of the light, the food culture, and the presence or absence of an air supply. Attention was also given to the question of the influence of some of the Bacteria and their destruction. Only after a large number of experiments had been made was it ascertained that due consideration had not been given to a factor, the importance of which cannot be overestimated, namely, temperature, and that to irregularities of temperature the repeated failure of the earlier experiments was without doubt to be attributed in a very large degree. The work which has since been resumed still needs careful attention to details of method before satisfactory results can be obtained, and in the meantime a short account of the experiments is given as a preliminary contribution to the subject.

The experiments will be considered, as far as may be, in the order in which they were carried out, while grouping them together according to different conditions, some reference to which is first necessary.

\section{Position.}

(A) In this room, where most of the earlier experiments were made, the aspect is north and the light moderate. The window was at all times kept partly open, and no artificial heating was used ; consequently the experiments were very susceptible to outside changes of temperature that occurred from one day to another. Records of the temperature of the water of the experiments were not made till the latter part of November, but twenty-five observations made between November 26th and January 13th showed a varying range of $6^{\circ}$ or more, $\dagger$ a maximum daily variation of $3 \cdot 8^{\circ}$, and a maximum change over two

\footnotetext{
* Journ. Mar. Biol. Assoc., N.S., Vol. VIII., p. 470.

+ All temperatures are recorded in degrees Centigrade.
} 
days of $5 \cdot 8^{\circ}$, the average temperature being $10 \cdot 8^{\circ}$. During the summer months, the changes must have been very much greater.

(B) Here the vessels rested on a table close to a large double window, with a western aspect, partly lighted also from the northern side, and the light was consequently good. The position in the building being more central than Position $A$, the changes in temperature were probably, on the whole, less in extent and less sudden than in the latter. At times, however, they were greater, as, for example, in the month of July, when on four successive days the following temperatures of water in the bell-jars were recorded : July 17 th, $25^{\circ}$; July 18 th, $20^{\circ}$; July 19 th, $16 \cdot 3^{\circ}$; July 20 th, $17^{\circ}$.

(C) In this part of the building, the General Laboratory, well lighted with large windows, both on the southern and on the northern sides, the light obtained was always good, and often so strong as to need screening. In the colder weather the air temperature is kept by hotwater pipes between $13^{\circ}$ and $18^{\circ}$, and in general it is subject to very much less change than in either of the other two positions. As, however, in all experiments here carried out, the vessels were kept submerged, either in the sea-water of the general circulation or in water artificially adjusted to a nearly constant temperature, the changes in air temperature were of minor importance and, as affecting the experiments, almost negligible. The water of the experiments, which was necessarily regulated by the temperature of the tank water, showed over a number of observations made between November 26th and February 7 th a varying range of no more than $1 \cdot 6^{\circ}$, a maximum daily variation of $1^{\circ}$, and an average temperature of $12 \cdot 3^{\circ}$.

\section{Vessels.}

These consisted chiefly of the following :-

$\begin{array}{ccc}\text { Glass Finger-bowls. } & \text { Capacity, } 350 \text { c.c. } \\ \text {, Flasks. } & \text { " } 1 \text { and } 1.5 \text { litres. } \\ \text { " Jars. } & \text { " } 2 \text { litres. } \\ \text {, Beakers. } & \text { " } & 2, \\ \text {, Bell-jars. } & , 11,\end{array}$

The vessels were covered with squares of glass or with watch glasses, as a provision against dust. Except in one special experiment (p. 562), there was no circulation of water through the vessels, the water being left standing, subject only to stirring by aeration or otherwise, and being only changed in certain occasional instances. 


\section{Water.}

(A) Tank Water.-Water circulated through the tanks of the Laboratory from the supply stored in the reservoirs. This water is pumped up into the reservoirs from the sea below the Laboratory at high water spring tides. In consequence of the large number of animals living in the tanks it contains a considerable amount of excretory products.

(B) Berkefeld Water.-Tank water treated with animal charcoal, and filtered through a Berkefeld candle. In many experiments, owing to the high salinity of the tank water, this was diluted with $5 \%$ distilled water.

(C) "Outside "Water.-Water brought in from outside the Plymouth Breakwater, and largely free from the contamination of the inshore grounds. This was used sometimes untreated, sometimes sterilised, and sometimes filtered through a Berkefeld candle.

(D) Miquel Sea-Water-Occasionally Berkefeld, usually "outside" water, treated with the modified Miquel solution employed by Allen and Nelson, * but chiefly used in considerably less strength, generally onethird, in experiments here to be considered.

\section{Light.}

Additional illumination was obtained when necessary by placing sheets of white paper or card, or of opal glass, under the vessels, and in many cases behind them also. In some experiments the light was partially or wholly cut off by screening the vessels with black paper.

\section{Food.}

In most of the experiments a culture of the Diatom Nitzschia closterium was used as food for the animals. In some, the Alga Chlorodendron subsalsum was used.

\section{Air-supply.}

Artificial aeration of the water was employed at intervals in many of the experiments for varying periods, and sometimes continuously, by means of drawn-out glass tubes led into the vessels, and connected with the general air-pressure system of the Laboratory. It may be said at once that no definite advantage seemed to be gained by its use, assuming the water to be naturally aerated at the outset.

* Journ. Mar. Biol. Assoc., N.S., Vol. VIII., p. 428. 


\section{The Experiments.}

For brevity, the results of the experiments will be considered in a summarised form, the experiments being grouped together according to the vessels in which they were carried out. The recorded averages and maxima refer to the life period in days occurring among animals of the several experiments in each group. The experiments carried out in Positions $\mathrm{A}$ and $\mathrm{B}$, in all of which the vessels were exposed to the influence of air temperature changes, will first be dealt with. Later, the experiments in Position C, in all of which the vessels were submerged, will be treated in the same manner, and the results of these will then be compared with those in Positions A and B. The dates given are those on which the different experiments were started.

\section{Positions A ANd B.}

In the experiments to be referred to, all but those made in 11-litre belljars were carried out in Position A. The results are marked with great irregularity. In certain exceptional cases, specimens lived for a considerable period, but the averages are almost consistently low, and it is evident that some factor entered into all the experiments which rendered the conditions unsuitable and in most cases quite intolerable. In some preliminary experiments in tank water, to which no Nitzschia or other food was added, rather lower averages occurred, but in other respects no distinct advantage was traceable to the kind of water used, which included Berkefeld, Berkefeld diluted, the same with Miquel-Allen solution in full proportions, "outside" water untreated, and the same sterilised. Some species appear to be more delicate than others, and among nauplii the mortality was exceptionally high. The different forms will, therefore, be considered separately.

Zoaeae. These should perhaps be viewed in a different category from the rest, since it is doubtful whether a suitable food was found for them, though Nitzschia, Chlorodendron, and Ciliate cultures were tried. In a total number of 18 experiments with from 4 to 11 specimens, in fingerbowls (June 11th to July 30th), the average time of survival was from 5 to 7 days, the maximum ranging from 11 to 16 days.

Calanus finmarchicus. In finger-bowls, 5 experiments comprising from 5 to 12 specimens (June 19th to August 7th) showed in Berkefeld, Berkefeld diluted, and Berkefeld diluted plus Miquel-Allen solution, comparatively little difference of average, 11 to 14 days, from that of 3 experiments in tank water (10 days), to which no Nitzschia or other 
food was added. Apart from one exceptional example in which a specimen, infected with the parasite Microniscus, lived for 40 days, the maximum was no higher than 23 days, which was 4 days in excess of the next highest period.

In 1-litre flasks, 5 experiments in "outside" water, containing from 3 to 5 specimens (September 27th to October 23rd) showed a higher average, of about 22 days, than was obtained in the finger-bowls, and a much higher maximum of 84 days. In the experiment in which this high maximum occurred (October 21st) the shortest life period was 23 days, and the average for the three individuals was about 44 days. No clear explanation was found for the fact that in three other Calanus experiments, started two days later under almost identically similar conditions, the maximum was no higher than 27 days, and the average about 16 days.

Temora longicornis. In finger-bowls, 9 experiments with from 6 to 12 specimens (June 19th to August 8th) were far less successful than in the case of Calanus, and a maximum of 23 days, which was obtained in one case in Berkefeld water, was far in excess of the life period that was usually sustained. The data for averages are incomplete, but with the exception mentioned the longest life did not exceed 11 days, and the average for all the experiments was probably not above 5 days.

In 1-litre flasks, 2 experiments, with 7 and 10 specimens, in sterilised " outside" water (September 18th and 27 th), were little more successful than those in the finger-bowls, the maximum being about 17 days, and the average life probably not exceeding 5 or 6 days. In connection with the mortality of this species, it is very remarkable that in the first of these two experiments, 6 Acartia which were included in the same vessel at the same time subsequently reached the high average of about 60 days.

In 11-litre bell-jars (Position B), an experiment with 70 specimens, in Berkefeld water (July 17th) failed completely, all dying within two days. Of a similar number, placed in the same bell-jar with the same water (July 19th), none lived for more than about a fortnight. In an experiment with 50 specimens in "outside" water (July 17th), a few only survived the first fortnight, though a single specimen lived for 48 days. Mention has already been made (p. 557) of the irregular and high temperatures that were recorded for the water in bell-jars in this position at this period, showing over four successive days a range of nearly $9^{\circ}$, with a maximum daily variation of $5^{\circ}$, and these irregularities were 
with little doubt accountable for the mortality of specimens, even in so large a volume of water.

Anomalocera Patersoni. In finger-bowls, 2 experiments with 6 and 3 specimens, were made in tank water only, to which no Nitzschia or other food was added (June 10th). These 9 specimens showed an average of 2 days only, the maximum being 4 days.

Acartia sp. In a 1-litre flask, a single experiment with 6 specimens in sterilised "outside" water (September 18th) showed the high maximum of 100 days, the average being about 60 days. This was the only experiment carried out in Position A in which nauplii were certainly produced, a few of these being observed continuously from the 30th to the 73rd days. The number of nauplii produced, and their individual life periods are uncertain. No more than four were recorded at any one time. Some showed distinct growth, but none reached an advanced stage. As it has been stated, 7 Temora which were included with these Acartia, all died within about 17 days, and it would seem on the evidence of this single experiment that the species (probably A. Clausi) is more hardy than Calanus or Temora. The experiment lasted till December 27 th

Nauptii (chiefly Balanus, Temora, and Calanus). In finger-bowls, 3 experiments with from 15 to 20 specimens in Berkefeld water (July 11th) showed a maximum of 4 days ; in 3 experiments, with from 20 to 100 specimens, in Berkefeld diluted (July 19th to 30th), the maximum was about 15 days; in 2 experiments, each with 20 specimens, in Berkefeld diluted, plus Miquel-Allen solution (August 8th), the maximum was about 12 days. The average for all these experiments probably did not exceed 2 days. On the other hand, as it has been shown, among the Acartia nauplii hatched from eggs laid in the vessel, some appear to have lived for a considerable time though the individual life periods were not known.

Young Calanoids. In 1-litre flasks with several young forms naturally contained in this bulk of "outside" water, and with no additional food included, 2 experiments (September 24th) showed a maximum life period of 18 days only.

In a bell-jar (Position B) an experiment in Berkefeld water with mixed plankton including many young forms, and with some fine townetting added as food (June 10th), showed several young forms, including nauplii, alive and healthy on the 33rd day, and a few continued till the 42nd day. Soon after this all disappeared, the specimens apparently 
failing, like others previously referred to, in consequence of high and irregular temperatures at the time in this position.

General. As bearing on the sensitiveness of some Calanoids to sudden changes in the water conditions, the following example is important. On June 15th, two Calanus finmarchicus were given to me by $\mathrm{Mr}$. Fuchs in a large jar (breffit) of 2000 c.c. in capacity, in " outside" water containing a growth of Nitzschia, in which he had reared some Echinoplutei. The culture had been started by him on April 19th, and kept from that date on one of the slate slabs in the General Laboratory. In the water that was used the two Calanus had been introduced unobserved, evidently as young forms, possibly as nauplii, and these, feeding on the Nitzschia culture, had grown to nearly full size. On June 15th the jar was taken over by me and placed in Position A, where the Calanus continued healthy until July 9 th. The Nitzschia having then grown too thick the Calanus were transferred to a new culture in Berkefeld water, in a clean jar. One specimen was stunned by the change, and fell to the bottom, remaining almost motionless afterwards, and both died within two days. The temperatures had been taken, and Mr. Matthews having kindly analysed samples of the water and ascertained the densities, the change of conditions from one jar to the other proved to have been as follows :-

$\begin{array}{lccccc} & & & \text { T. } & \text { S.\% } & \sigma_{\mathrm{t}} \\ \text { Jar A. "Outside " } & \text { water } & 16.5 & 35 \cdot 22 & 25 \cdot 82 \\ \text { Jar B. } & \text { Berkefeld } & \text { " } & 17.5 & 37.94 & 27 \cdot 68\end{array}$

The temperature change being one of only $1^{\circ}$, it seemed evident that the death of these Calanus was to be attributed to a sudden change of 2.72 in salinity, and owing to this the Berkefeld water subsequently used in the experiments was diluted with $5 \%$ distilled water. It was thought that by thus obviating such sudden changes in salinity, much of the difficulty previously encountered in the experiments might be overcome. It was not realised till later that repeated changes in the air temperature communicating themselves less suddenly to the water in the exposed vessels might be equally harmful in their effects.

\section{Special Experiment in Position A.}

In the latter part of the year, it became increasingly evident that some factor which had escaped observation was a constant source of harm to the animals. In view of the possibility that this might be the presence of Bacteria, several experiments, which will be referred to in detail later, had been made in keeping Copepoda in the presence of strong cul- 
tures of Bacteria raised on peptone. But the results of these experiments showed that species were capable of tolerating such conditions to a much greater degree than was expected, and did not bear out the supposition that bacterial infection had been the primary cause of failure. Experiments also made with and without an air-supply gave no definite evidence of the value of an air-supply as improving the conditions in water that was naturally aerated at the outset.

There remained a possibility that harmful conditions might be produced through the accumulation of excretory products in the vessels, and to test this a special experiment in Position A was arranged, by which a constantly changing supply of water and food was passed through the vessel in which the animals were contained. For this purpose a large bottle, of 10 litres in capacity, was filled with sterilised "outside" water, with Miquel-Allen solution in proportions one-third of those used by Allen and Nelson, and this water was infected with a culture of Nitzschia. The vessel of the experiment, in which 5 Calanus were placed, was a 1.5-litre flask, and into this the supply was led by a glass tube from the large bottle, the apparatus being arranged in the form of a self-regulating siphon, by which the water in the flask was kept at a constant level. From close against the bottom of the flask, a siphon tube was led out from the flask to the exterior, to serve as a waste pipe, and this, drawing on the contents of the flask, was so adjusted by a screw clip that the water and food-supply was made to pass through the flask at the rate of 1 litre per diem, nearly. An air-supply was also provided at a slow rate in the flask by connection with the airpressure system of the Laboratory. A good light was ensured and, the food growth being strong, the conditions were such as appeared to meet all requirements. But little improvement was shown in the result of this experiment which, though more successful than most of the previous ones, produced only a maximum life of 28 days, and an average of about 21 days, the shortest life being 14 days. This experiment was started on October 16th, 5 days prior to the commencement of an experiment made in the same position, in a 1-litre flask under the ordinary conditions, in which 3 Calanus subsequently showed a maximum of 84 days, and an average of 44 days (p. 560).

\section{Position C.}

It had in the meantime been observed that a Calanus which had been left in a 2000 c.c. jar, partly submerged in one of the tanks in the General Laboratory on August 28th, was still alive on October 18th, 
51 days later, and, soon after the close of the special experiment just described, a new series was started with the vessels submerged up to the neck in the same manner. An improvement in the results soon became apparent, and from this time the experiments were continued under these altered conditions, either in one of the tanks or in a small extemporised reservoir of water.

In the first experiment, with 6 Temora, in a 2-litre jar of water, with Chlorodendron as food, one specimen only was alive on the 19th day, and this did not live for more than a few days afterwards. These Temora, however, had been left standing for 7 days previously, in a beaker in Position A before the experiment was started, and the result was therefore of doubtful value.

The other experiments related chiefly to Pseudocalanus elongatus and Calanus finmarchicus. The water used was in all cases "outside" water, treated with one-third Miquel-Allen solution and filtered through a Berkefeld filter. In the majority of the experiments the food was Nitzschia; in a few cases Chlorodendron was used. Exact data for averages are wanting, and the results can only be considered in their main details. In many cases the observations were unfortunately interrupted before the complete records had been obtained. The results may be summarised as follows :-

Pseudocalanus elongatus. In 2 -litre beakers, 3 experiments, each with 15 specimens (November 11th to 28 th), showed on the 44th, 50th, and 51st days, severally, about 23 survivors. In one of these experiments, the water having been changed on the 44th day, four were still living on the 72nd day. In another a change of water on the 51st day led to bacterial infection, with fatal results to all the specimens very soon afterwards. In the third, one specimen was still living on the 121 st day.

In an uncompleted experiment with 20 specimens (December 20th) a few were still living on the 50th day.

Two experiments (Nos. 174 and 175), which failed through injury caused in connection with an air-supply, are referred to below.

Nauplii were obtained in all the experiments with Pseudocalanus, their presence and growth being observed over periods which varied from 40 to 63 days in the different experiments, omitting the two experiments last referred to. Data concerning individual life periods are not available, but several were recorded as reaching the adult form and, in a few cases, apparently the full growth, the age at which the adult stage was reached being approximately between 35 and 40 days. 
In the experiment in which the loss of the specimens was attributed to bacterial infection, bright carmine patches appeared colouring the dead bodies of the specimens, other objects at the bottom of the vessel being suffused with the same colour. Mr. Harold Drew kindly tried to cultivate the Bacteria on peptone agar, but no growth was obtained.

The circumstances of the failure of the two experiments (November 30 th) in connection with the use of an air-supply are as follows :-

Each experiment concerned 20 specimens.

(No. 174.) Till the 14th day, several were seen very active, and on this day from 20 to 30 nauplii were observed. On the 15th day, all the nauplii and nearly all the adults were dead. On the 19th day, only one of the adults remained alive, showing little movement, on the bottom of the vessel.

(No. 175.) On the 14th day, about a dozen adults and a few nauplii were seen. No subsequent records were made till the 19th day, when nearly all were dead. On the following day a few nauplii still survived, but these died soon afterwards.

In these two experiments the vessels had been provided with an air jet, forced through the water by connection with the air-pressure system of the Laboratory, during the 24 hours between the 13th and 14th days. When on the 14th day the air-supply was taken off, and the vessels removed from the tank for examination, they remained exposed for about half an hour to the much higher air temperature of the Laboratory. The rise in the temperature of the water thus caused was not observed, but it seems possible that the air-saturated water of the vessels thus parting rapidly with air in solution, injury was caused to the blood system of the animals.

Calanus finmarchicus. In 2-litre beakers, submerged in the tank, 5 experiments (November 30th to January 13th) resulted, as far as the observations were carried, as follows :-

\begin{tabular}{ccccccc} 
Experiments. & \multicolumn{3}{c}{$\begin{array}{c}\text { Specimens. } \\
1\end{array}$} & \multicolumn{2}{c}{$\begin{array}{c}\text { Max. Period of Life } \\
\text { Recorded, days. }\end{array}$} & $\begin{array}{c}\text { Average, } \\
\text { days. }\end{array}$ \\
1 & $\ldots$ & 2 & $\ldots$ & 48 & $\ldots$ & 35 (completed) \\
1 & $\ldots$ & 5 & $\ldots$ & 27 & $\ldots$ & 19 \\
2 & $\ldots$ & 3 & $\ldots$ & 64 & $\ldots$ & 41 (uncompleted)
\end{tabular}

Ova were obtained in the last two experiments, but were lost through an accident.

In 1-litre flasks submerged in a bath heated over a small bunsen flame to $16^{\circ}-18^{\circ}$, and kept by a regulating thermometer at this approximate 
temperature, five experiments (January 13th to 29th) showed the following results up to the time when the observations were interrupted :-

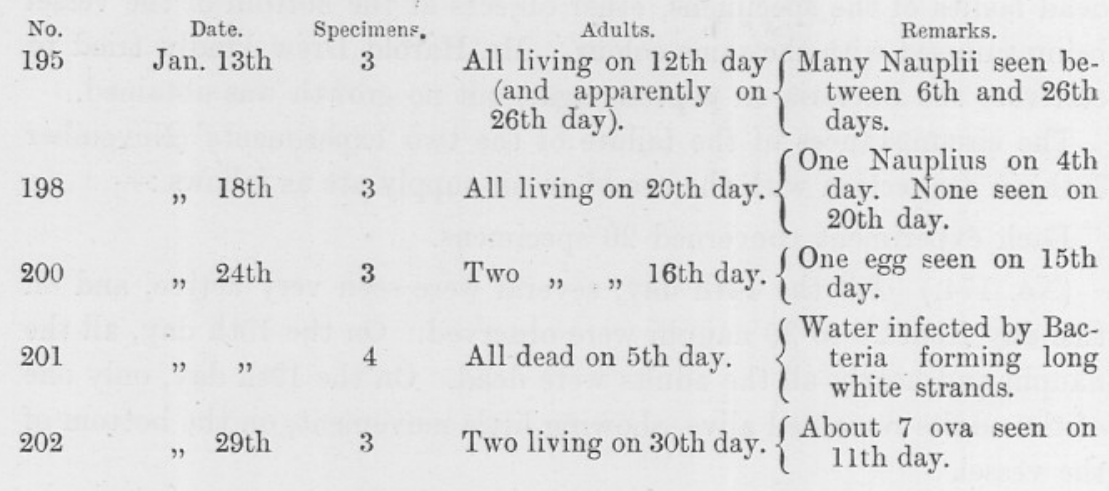

Omitting the experiment which failed through bacterial infection, the mortality was small at the time when the observations were interrupted, two deaths only having been recorded among the twelve specimens over a period averaging at least 20 days and probably 23 days, in the different experiments.

Ova were obtained in all these experiments, and nauplii were recorded in two of them, many occurring in one over a period of 20 days.

Acartia sp.* In a 1-litre flask, submerged in the artificially heated bath, a single experiment was made (December 20th) with 5 specimens. On the 40th day three of these were living. Nauplii were first observed on the 23rd day, about a dozen were seen on the 25th and 32nd days, and a few only on the 40th day.

\section{A Comparison of the Results obtained in Position C with those obtained in Positions $\mathbf{A}$ and $\mathbf{B}$.}

The experiments with Pseudocalanus having all been made in Position $\mathrm{C}$, the results obtained with this species must be treated with some reserve when comparing them with those obtained for other species in Positions $\mathrm{A}$ and $\mathrm{B}$, and it is better to consider them only as confirming the evidence of the experiments with Calanus and the single experiment with Acartia.

For Acartia, the only experiment in Position A gave the high maximum of 100 days, and an average of 60 days for the 6 specimens. In the uncompleted experiment in Position C, 3 out of the 5 specimens were still living on the 40th day. The combined life period of the young

\footnotetext{
* Probably A. Clausi. The species was not certainly determined.
} 
was in the former case 43 days, and in the latter 17 days when the last record was made. It is only noticeable that in Position $\mathrm{C}$ the fertility of the parents was distinctly higher than in Position A. It seems probable that the species is hardy as compared with others and less susceptible to injury from changeable conditions (cf. p. 561).

For Calanus, the comparative results are as follows :-

\section{Position A.}

(1) Finger-bowls. Max. for 5 experiments (34 specimens), 40 days. Avg. 12 days.

(2) 1-litre flasks. " " 5 " $\quad(19 \quad, \quad), 84 \quad, \quad 22$ "

(3) Special expt. " $\quad 1 \quad$ ( $5 \quad, \quad$ ), $28 \quad, \quad 21$,

Average for 11 experiments, 17 ,

\section{Position C.}

(1) 2-litre beakers. Max. for 2 completed exps. ( 7 specimens), 48 days. Avg. 27 days. Of 3 uncompleted experiments, one with 3 specimens showed at the time of the last record an average of 41 days; the other two, with 8 specimens, showed on the 45th day an average of 40 days.

The average for these 5 experiments then exceeded 35 days.

(2) 1-litre flasks. The 4 experiments (12 specimens) were very incomplete at the time of their interruption, only one death having occurred in each of two of them, on the 16th and 30th days respectively, or over a period averaging in the 4 experiments not less than 20 (or 23) days.

The 5th flask experiment is omitted from consideration here. The Bacteria by which the water became infected appear to be comparatively uncommon, and, if the general form of the strands produced by them can be relied on as characteristic, they were only twice observed, each time with fatal results to the animals.

Disregarding the last experiment, it may reasonably be estimated that the average for the 4 experiments with Calanus in 1-litre flasks would not have been less than that shown by the 5 others in Position $\mathrm{C}$ at the close of the observations, viz., 35 days.

In regard to experiments in Positions $\mathrm{A}$ and $\mathrm{B}$ generally, the early falling off of specimens is noticeable in nearly all the results, thus :-

For Temora, the average of 9 experiments in finger-bowls was not more than about 5 days ; that of 2 experiments in 1-litre flasks was about the same; in 2 experiments in 11-litre bell-jars, few survived the first fortnight.

With Anomalocera, the 2 experiments with 9 specimens in finger-bowls showed an average of 2 days only, with a maximum of 4 days.

With Nauplii, especially those of Balanus, Temora, and Calanus, introduced direct from the townettings into finger-bowls, the mortality 
was very high, none living for more than about 15 days, and the average for 8 experiments probably not exceeding 2 days. The few, on the other hand, obtained in the course of the experiment with Acartia, lived for a considerable time. In a few experiments in Position A with mixed plankton kept in its natural proportions, in the water that contained it, from 1 to 3 nauplii were observed alive in 3 different experiments in 1-litre flasks, after 11, 11, and 17 days severally ; their continuance in these cases being possibly due to the absence of the initial change of water that was made in the ordinary experiments. On more than one occasion, when nauplii were transferred from townettings to water of a different (higher) temperature, they were seen to be temporarily stunned by the change, and to fall to the bottom of the vessel, though usually recovering within some 5 or 10 minutes afterwards.

Young Calanoids generally, included with some mixed plankton in an 11-litre bell-jar of Berkefeld water in Position B, showed a comparatively high maximum in this larger volume of water, several, including nauplii, surviving on the $33 \mathrm{rd}$ and a few on the $42 \mathrm{nd}$ day.

There remain for consideration the experiments in Position $\mathrm{C}$ with the species Pseudocalanus elongatus, for which unfortunately there are no comparative data in the other positions. Of the 6 experiments which have been referred to, 2 may be omitted in which a sudden failure was attributable to the use of an air-supply. In 3 of the remaining 4 experiments, about $50 \%$ of the total number of specimens were alive on the 50th day, some being afterwards recorded considerably later; in the 4th probably $30 \%$ were alive on the 50th day. Young, which were obtained in all the experiments, were recorded in these four over periods ranging from 40 to 63 days in duration, one or more in each case reaching the adult stage.

\section{General Remarks.}

While it is not improbable that other adverse causes, in addition to that of changeable temperature, contributed in some measure to the generally unsuccessful results of experiments in Positions A and B, it is difficult to trace them with any consistency, or to attribute the failure of the animals to any single chief cause other than the fluctuations of temperature occurring in vessels which were directly exposed to air changes.

Experiments with some of the common putrefactive Bacteria, cultivated on peptone, in no way bore out a supposition that the presence of such Bacteria, and their fouling effects on the water, had exercised any important influence on the progress of the experiments. The possibility 
of infection by Bacteria of a different nature, such, for example, as the two forms referred to (pp. 565, 566), must of course be considered. But such forms as these were rarely observed, nor did the very irregular rate of mortality among individuals in an experiment, or in different experiments, suggest that bacterial action was primarily accountable for the death of the specimens.

Food-growth again, was in many cases poor and uncertain in experiments in Position A, but as the food-supply was with few exceptions renewed at frequent intervals, it seems unlikely that the animals were much affected by any such deficiency. It was often observed, too, that when food-growth was vigorous the animals died off independently of this, or even earlier than in experiments in which the growth was poor or stationary.

A noticeable feature occurs in connection with the special experiment in Position A (p. 562), in which, apart from temperature, apparently ideal conditions were provided, and a healthy growing food culture was carried in the changing water-supply through the vessel in which the animals were contained. This vessel was a 1.5-litre flask, and it is remarkable that the average life of the 5 Calanus it contained was very nearly the same, 21 days, as that for the 19 specimens of the 5 experiments with this species in 1-litre flasks in the same room, 22 days. In the 5 experiments with 34 specimens in finger-bowls, in which the volume of water was no more than 300-350 c.c., the low average of 12 days is presumably attributable to the changes communicated by the air temperature being more rapid than in the case of the larger vessels. If an instantaneous change of temperature, probably of $4^{\circ}$ or $5^{\circ}$ (p. 568), can so affect nauplii as to stun them for 5 or 10 minutes, or if one, apparently of salinity only, can be fatal, as in the case of the 2 Calanus referred to (p. 562), it is reasonable to suppose that the daily fluctuations of air temperature to which uncovered vessels are exposed are liable to produce conditions that must sooner or later prove fatal to animals so sensitive to such changes.

The removal of the experiments to Position $\mathrm{C}$ was especially prompted, as it was observed, by the survival of a Calanus for 51 days in a 2-litre jar submerged in one of the tanks. This specimen was then found to have the hairs of the antennæ and caudal rami much encrusted with fixed Diatoms and other accretion, and probably succumbed owing to these causes about a week later. This jar contained a sample of water only, with the plankton naturally present in it, and therefore very few individuals at the outset, nor was any addition made to the food. Yet on 
the 29th day there were seen alive in it, besides the adult Calanus, a few small ones, and one or two Temora, the latter being a species for which very low averages had been obtained elsewhere.

In the experiment carried out by Dr. Allen (p. 556), in which some Calanus were kept alive for not less than about 50 days, and in which two of the nauplii reached the adult stage, the flask used was kept standing in the water of one of the tanks. In the case of the 2 Calanus that were raised by Mr. Fuchs in an Echinopluteus culture, the jar containing these was not submerged, but was kept standing on one of the slate slabs under the tanks in the same room. Here these two specimens lived for 57 days, and subsequently in Position A for another 24 days, making a total period of 81 days. It is not known how far this result may have been exceptional, like such examples as that in which a specimen lived for 84 days in a 1-litre flask in Position A, but probably, under such conditions, the temperature changes in the water of a jar of 2000 c.c. would at most times be slight and gradual, and not such as seriously to affect the animals.

For the 5 experiments with Calanus in vessels submerged in the tanks the average, 35 days, is very incomplete, three of the experiments being uncompleted. For the 4 experiments in vessels submerged in the artificially heated bath, the low mortality at the time of their interruption suggested an average not lower than was indicated in the others, which at the close of the observations stood at rather more than double the average ( 17 days) obtained for the 11 experiments with this species in Position A.

As a series of preliminary experiments, the results with Pseudocalanus may, on the whole, be regarded as fairly satisfactory, the small proportion of nauplii which were brought through to the adult form being probably due to minor imperfections only in the conditions, possibly in the food-supply which it should not be difficult to adjust.

The results of the experiments in Position $\mathrm{C}$ are not as conclusive as might be wished, but their difference as a whole and in detail from the others is so marked as to leave little doubt that the preservation of an even temperature is of the first importance in experiments with pelagic Copepoda, and probably indispensable to success with the majority of pelagic plankton species.

\section{. On Diatom Growth in the Experiments.}

In nearly all the experiments in Position $\mathrm{C}$ with Calanus finmarchicus considerable difficulty was encountered in controlling the growth of the 
food-supply (Nitzschia). Notes as to exact dates are incomplete, but the rapidity of growth seems to have become especially apparent during the second week, the Nitzschia then becoming so thick as soon afterwards to necessitate the pouring off and renewal of the water. This was very pronounced in the flasks submerged in the bath heated to about $18^{\circ}$. Under the latter conditions, a flask containing only Nitzschia was recorded on the 12th day merely as "growing well," and another which was taken over for use in an experiment on the 15th day without comment was presumably in the same condition. In all of 4 flasks, however, which contained Calanus at this time-3 specimens in eachthe growth became very thick on the 11th or 12th day, and soon afterwards so dense that it was very difficult to discern the specimens. In the same bath with these flasks was the one containing 5 Acartia, in which the specimens did well and produced several nauplii, yet in this case the growth was on the 40th day so slight that the Nitzschia was then renewed. Similarly, in all the experiments with Pseudocalanus (4 with Nitzschia) no pronounced growth of the Diatom occurred during the long period for which this species was kept.

While this overgrowth of food in experiments with Calanus was a serious hindrance and probably interfered considerably with the preservation of healthy conditions, the fact has a greater importance in its bearing on Diatom growth. Further investigations are needed before any very definite conclusions can be drawn from these limited data, but the facts suggest the presence of a strong fertilising action directly or indirectly traceable to the excretory products of Calanus finmarchicus, which, though probably occurring also in other species, seems not to occur in Pseudocalanus, or, judging from one experiment, in Acartia.

The water used in all these experiments was " outside" water, sometimes sterilised, always with the addition of one-third Miquel-Allen solution, that is to say, in the proportions of 2 c.c. of Solution A and 1 c.c. of Solution B to 3 litres of sea-water, the water being then filtered through a Berkefeld filter. How far the action arises independently of Miquel is not yet clear. In two later experiments, each with 5 specimens, in 2 litres of unfiltered sterilised "outside" water only, a similar intense growth was obtained. In consequence of this, it was decided to suspend the use of Miquel, and using only filtered unsterilised "outside" water, to reduce the number of specimens. In experiments made under these latter conditions, with 1 or 2 Calanus in 2 litres of water, the growth has. been more often slight or moderate, though sometimes so strong 
as to necessitate partial screening from the light. The intense growth obtained in one-third Miquel water occurred in experiments either with 3 Calanus per litre, or with from 2 to 5 Calanus per 2 litres. During the transition, which was a gradual one, from one-fourth Miquel to pure "outside" water, a thick growth was still obtained in an experiment with 1 Calanus in 2 litres, when it was estimated that a trace only of Miquel remained in the water.

The exact bearing which these facts may have on the problems of Diatom growth which are under investigation by Dr. Allen* will, it is hoped, become more apparent as the experiments are continued. That the action of the Calanus excreta is such as greatly to intensify the growth in the presence of the Miquel salts, even when the latter are used in much reduced proportions, there seems to be no doubt. Whether it is quite an independent one is at present somewhat uncertain. $\dagger$

The Influence of some Bacteria on the Experiments, and their Destruction.

In order to ascertain the possible influence of some of the common Bacteria as contributing to the unsuccessful results of the earlier experiments, some special experiments were carried out in which Bacteria were encouraged to grow in large numbers in the water. As a food basis a stock solution of peptone, of 5 grams per litre in strength, was prepared in diluted Berkefeld water, and this was used in very small quantities.

In some peptone-agar cultures which Mr. Drew kindly made for me, from some infected water, two forms of Bacteria were obtained: one producing large spreading, roughly circular, white colonies, from 1 to 5 millimetres in diameter; the other forming small compact, often almond-shaped, yellowish-white colonies, usually about half a millimetre in greatest measurement.

Three 1-litre flasks of diluted Berkefeld water were infected with both of these forms, peptone being added in the percentages of $\cdot 001, \cdot 002$, and $\cdot 01$, severally. On the following day the water in all the flasks was clouded with Bacteria.

In the first of these experiments ( $\cdot 001 \%$ solution) the cloudiness continued unchanged on the 58th day. On the 68 th day, it had nearly disappeared, and the peptone being then renewed in the same proportions, the bacterial growth was restored, and continued on the 90th day subsequently.

* Cf. Journ. Mar. Biol. Assoc., N.S., Vol. VIII., p. 421 ; Vol. X., p. 417.

+ The most recent experiments support the view that the action is an independent one.-L. R. C. 
In the second experiment $(\cdot 002 \%$ solution) the cloudiness still continued on the 68th day, and the peptone being then renewed, there was no falling off in the Bacteria on the 90th day afterwards.

In the third experiment $(\cdot 01 \%$ solution) the cloudiness was unchanged on the 47 th day, and the water was then inoculated with 20 c.c. of a culture of a Ciliate, Euplotes sp. On the 9th day subsequently the water was found to be cleared of Bacteria, the Euplotes being present in very large numbers, but owing to my temporary absence in the interval it was not known at what period exactly the water became cleared. This experiment.is of interest as exemplifying the destructive action of a Ciliate on a Bacteria culture of long standing.

In all experiments in which Bacteria were grown on peptone, or on the macerating remains of dead plankton, the same action occurred on the part of Infusoria, either naturally present or introduced into the water. Those purposely introduced were from mixed cultures only, in which one or more species were especially prominent. Such a culture was that of Euplotes, which was kept for a long period in a flask in Position A. Another large species, apparently a Strombidium, was usually obtained in large numbers in "outside" water in which Bacteria were grown, but some difficulty was encountered in retaining this indefinitely as an active culture and often, after a varying period of multiplication, it was lost sight of or died, being then usually superseded by a culture of smaller forms.

Experiments were made partly in sterilised, partly in unsterilised water. Of those here to be considered, 12 were made in 1-litre flasks in Position A, and 2 were made in 11-litre bell-jars in Position B. Peptone was used in proportions varying from $\cdot 001 \%$ to $\cdot 0001 \%$, usually in the former percentage, the Bacteria growth being induced by it in some cases once only, in others as many as six times in the same experiment.

The period occupied by Infusoria in clearing the water varied somewhat in the different experiments, apparently also in proportion to the strength of the peptone. Not always exactly observed, the period ranged in 15 exact records, from 3 to 8 days, the average being 6 days, from the time when the peptone was added, the Bacteria usually assuming a very strong growth within 24 hours later.

In some experiments in which this cycle of events was repeated a few times, a point was reached when the culture became "sick" and stagnant, the Bacteria growth being feeble, and the Infusoria falling off. 
But in most cases the same process was repeated as far as the experiments were carried.

In experiments with sterilised water, the Infusorian mostly employed for inoculation was of the form which was referred to Strombidium, including probably two, if not three, distinct species. This Ciliate, though often lost sight of and superseded by smaller forms, was retained in some experiments for a long period. In one case it continued fairly numerous as late as the 67th day, after having cleared the water of four successive cultures of Bacteria which were grown on peptone introduced on the 1st, 13th, 39th, and 49th days, severally.

Following the destruction of a strong Bacteria culture by Infusoria, there arises commonly, if not invariably, a more or less heavy deposit of flocculent white patches in the water. The nature of this deposit, possibly the excretory product of the Infusoria, was not ascertained. In one experiment which had been five times impregnated with peptone within a period of 29 days, a sixth impregnation of the water decanted off to a clean flask on the 34 th day did not produce any distinct Bacteria growth, or any recurrence of the Infusoria, the water remaining sickly in appearance. But a similar addition of peptone to the original flask with its deposit, which had been refilled with clean sterilised "outside" water, produced a strong Bacteria growth, the Infusoria continuing fairly numerous for some 3 weeks later. In the former case conditions had apparently arisen in the water, such as to resist further Bacteria growth, the Infusoria being consequently deprived of their food-supply.

These observations, though passing beyond the range of the subject of this paper, seem to deserve notice, as emphasizing the intimate relationship existing between Infusoria and Bacteria in the sea, and the destructive action of the former on the latter in experiments. This bactericidal action may be peculiar to certain species, or again may not in these be an essential feature of their natural existence: Euplotes, for example, which is rapidly destructive of Bacteria, and will apparently thrive on them alone indefinitely, was at first found to be feeding largely on the spores of Chlorodendron. One point seems certain, that in so far as such Infusoria may occur in experiments, their presence is not in itself to be regarded as nocuous, but rather, on the contrary, as an indication of the presence of unhealthy conditions which they are directly engaged in counteracting.

As regards the influence of these common forms of Bacteria on the experiments with the zooplankton, specimens of Calanoida and other species, more especially small or young forms, were kept alive on several 
occasions in the presence of these cultures for a considerable period, in one case through 4 successive growths of Bacteria, extending over some 6 weeks, the maximum life recorded-strangely, in this lastmentioned experiment-being 48 days. Some notes concerning a few of these experiments are appended :-

\section{1-litre Flasks.}

(No. 141.) In sterilised "outside" water, impregnated once with peptone, on the 1st day, and cleared of Bacteria on the 9th day by Euplotes.

Of about 6 Calanoids which were introduced on the 13th day, 3 (Acartia) were alive and active 34 days later. The maximum life period was not recorded.

(No. 140.) In sterilised " outside " water, similarly impregnated once with peptone, and cleared of Bacteria on the 8 th day by a mixed culture of Infusoria.

Of about 12 Calanoids introduced on the 14th day, about 6 were alive after 7 days, 2 after 10 days, 1 after 20 days. The last was not alive on the 31 st day.

(No. 122.) In unsterilised " outside " water, impregnated twice with peptone, on the 1st and 21st days, and cleared by contained Infusoria on the 5th and sometime prior to the 30th day, respectively.

Of the Calanoids contained in the water at the outset, 2 or 3 adult Temora were alive on the 30th day, and 1 on the 33rd day.

The water was aerated for a time on the 21st and 23rd days.

(No. 121.) In unsterilised "outside" water, impregnated four times with peptone, on the 1st, 28th, 33rd, and 38th days, severally, and cleared by contained Infusoria about 5 days later in each case.

Of several small forms in the contained zooplankton, 1 Balanus nauplius was recorded alive as late as the 21st day; a few Calanoids were alive on the 28 th day ; and 2 Calanoids were alive on the 48 th day. The water was decanted off into a clean flask on the 8 th day.

\section{1-litre Bell-jars.}

(No. 145.) In unsterilised "outside" water, impregnated with peptone on the 1st day only, and cleared by the contained Infusoria on the 7 th day.

20 or 30 small Calanoids were alive on the 10th day, about 4 on the 29th day. None were observed on the 42nd day.

(No. 144.) In unsterilised "outside" water, impregnated with 
peptone on the 1st day, and again in smaller quantities on 5 days successively, from the 8 th to the 12 th day.

5 small Calanoids were observed alive on the 42 nd day.

In both of these last-mentioned experiments the water became extremely foul on the 3 rd day especially. In the second it was siphoned off and back into the bell-jar on that day, for aeration. In the first, it was not disturbed.

In these extreme cases, in which the Bacteria were grown, sometimes repeatedly, in enormous numbers, the specimens were directly exposed to the chemical changes produced in the water, apart from the intervals when it was cleared, for about 4 or 5 days or longer as often as the Bacteria growth was renewed. In No. 121, for example, at least 2 Calanoids survived, after nearly 7 weeks, an aggregate period of intense Bacteria growth amounting to about 16 days. And in most cases the water was not aerated or disturbed. From those results and from others obtained in similar experiments, it seems evident that the influence of common Bacteria of this character, occurring in comparatively small numbers in the ordinary experiments, must be so slight as to be almost negligible; while the occurrence of Infusoria in the water can only be regarded as counteractive to them, and probably as beneficial in the presence of any unhealthy conditions that arise.

In all of these experiments no food was given other than was already present in those in which the water was unsterilised. Apparently the specimens were feeding on the Infusoria, and judging from the appearance of the excreta this seemed to be the case.

So far as they have been observed, the Bacteria which can be of serious harm to Copepoda in such experiments seem to be of infrequent occurrence in the water employed. Two forms only have been definitely recorded, to both of which allusion has already been made: the one forming irregular white slimy strands through the water (p. 566); the other giving a carmine-coloured tinge to objects attacked or invested (p. 565). Each of these has been twice observed, and both have proved in each case quickly fatal to all specimens that were contained in the infected vessel, though an endeavour to cultivate the second form has twice failed. 